Research Article

\title{
Adverse drug reactions: a retrospective review of hospitalized psychiatric patients at tertiary care hospital
}

\author{
Priyanka Pravinbhai Hotha*, Shilpa P. Jadav, Hiren R. Trivedi
}

Department of Pharmacology, Shri M. P. Shah Government Medical College, Jamnagar, Gujarat, India

Received: 05 July 2016 Accepted: 06 August 2016

\section{*Correspondence to:}

Dr. Priyanka Pravinbhai Hotha, Email: priyankahotha@ gmail.com

Copyright: (C) the author(s), publisher and licensee Medip Academy. This is an openaccess article distributed under the terms of the Creative Commons Attribution NonCommercial License, which permits unrestricted noncommercial use, distribution, and reproduction in any medium, provided the original work is properly cited.

\begin{abstract}
Background: Hospital data based monitoring of ADRs can shed light on their extensiveness and pattern of occurrence. Study is expected to enable us in obtaining information on the incidence and pattern of ADRs in the local population. The objective of this study was to do surveillance, detect incidence of ADR and to analyse the ADRs according to their demographic distribution, reporting, presentations and causality assessment scale.

Methods: A retrospective study conducted from January 2011 to December 2014 and psychiatric hospitalized patients were analysed and ADR reports were assessed for probability, severity, psychotropic drugs involved, and preventability.

Results: A total number of 101 ADRs were reported in 72 patients. Most common ADR were mainly tremor 14 (13.86\%), salivation $11(10.89 \%)$ followed by muscle rigidity $6(5.94 \%)$ and slurring of speech $6(5.94 \%)$. In majority of the instances, it was antipsychotic agents $41(56.94 \%)$ followed by antidepressants $11(15.27 \%)$ and mood stabilizers $11(15.27 \%)$. As per causality assessment, 95 (94.05\%) cases were 'possible' in WHO-UMC criteria and 72 $71.28 \%$ ) cases were 'possible' in Naranjo scale respectively. As per Schumock and Thornton preventability assessment, 91(90.09\%) of total ADRs were in the not-preventable category. As per Hartwig and seigle's severity assessment, majority of ADRs 74 (73.26\%) were mild in severity.

Conclusions: ADRs were most commonly associated with antipsychotic drugs. Developing an on-going ADR reporting system with continuous motivation and creating awareness among the healthcare professionals for reporting suspecting ADR will help to continue reporting and improving the patient's safety.
\end{abstract}

Keywords: ADRs, Drug interactions, Psychotropic drugs

\section{INTRODUCTION}

Adverse drug reaction (ADR), as defined by WHO, is "a response to a drug that is noxious and unintended and occurs at doses normally used in man for prophylaxis, diagnosis or treatment of disease, or for modification of physiological function". Pharmacovigilance has been defined by the WHO (2002) as the 'science and activities relating to the detection, assessment, understanding and prevention of adverse effects or any other drug related problems'.

ADR are a major cause of morbidity and mortality worldwide approximately 5\% (range 2\% - 20\%) of reported hospitalizations are because of an ADR and at least one ADR has been reported to occur in $10 \%-20 \%$ of hospitalized patients. An ADR is associated with a significantly prolonged length of stay, increased economic burden, and almost two fold increased risk of death. $^{2}$

Pharmacovigilance helps in early detection of ADRs and identification of risk factors. Underreporting of ADRs can be improved by imparting knowledge regarding pharmacovigilance to healthcare professionals. ${ }^{3}$

Adverse drug reaction monitoring and reporting activity is in its infancy in India. The important reason is lack of awareness and lack of interest of healthcare professionals in ADR reporting and documentation. ${ }^{4}$ In order to improve the reporting rate, it is essential to improve the knowledge, attitude, and practices (KAP) of healthcare 
professionals regarding ADR reporting and pharmacovigilance. ${ }^{5}$

Pharmacovigilance in psychiatry units can play vital role in detecting adverse drug reactions and allowing physician to possibility and circumstances of such events, thereby protecting the user population from avoidable harm. ${ }^{6}$ Adverse reactions are one of the main factors which prompt patients to discontinue the medications. ${ }^{7}$

ADRs in hospitalized psychiatric patients are not only common, but they also have a high rate of preventability. A health care system can use data on frequency, severity, probability, and preventability to identify medications that should be targeted for quality improvement projects and patient education. Targeting high-risk medications that have been identified through analysis could have a significant impact on reducing preventable ADRs. ${ }^{8}$

The present study was carried out to study the incidence and the pattern of ADRs taking place in psychiatry units of tertiary care, teaching hospital, Jamnagar over a period of four year. It was thought that this hospital data based monitoring of ADRs can shed light on their extensiveness and pattern of occurrence. Such a study is expected to enable us in obtaining information on the incidence and pattern of ADRs in the local population. The present evaluation was also considered to provide opportunities for interventions especially for the preventable ADRs which will help in promoting safer drug use. The observations made, if disseminated to other healthcare professionals may help improve the quality of patient care by ensuring a safer use of drugs. Finally, similar reporting exercises may become necessary to educate and to increase the awareness about ADRs to all the concerned patients.

The objective of this study was to do surveillance and detect incidence of adverse drug reactions in Indoor patient's data of Psychiatry department. And to analyse the ADRs according to their demographic distribution, reporting and presentations and causality assessment scale.

\section{METHODS}

Source of patient's data was collected from the medical record department at tertiary care hospital.

Type of this study was retrospective study.

Duration of this study was a retrospective review was conducted of ADR reports from January 2011 to December 2014.

Sample size of this study was all patients' data satisfied inclusion criteria attending indoor patient department of psychiatry at tertiary care hospital during study period from January 2011 to December 2014.

\section{Inclusion criteria}

Patients admitted and receiving any psychopharmacological agents with a diagnosis of psychiatric illness.

All the patients who either had developed a clinically suspected adverse drug reaction after admission or was admitted primarily because of an ADR.

\section{Exclusion criteria}

- Diagnosed cases of mental retardation and dementia

- Patients on stimulant drugs.

Permission was obtained from medical superintendent and heads of psychiatry units. A retrospective review was conducted of ADR reports from January 2011 to December 2014 at tertiary care hospital. All patients' data those admitted to the Psychiatry units during the study period was included. The investigator visited the Medical record section daily and studied every patient from admission to discharge from January 2011 to December 2014. In all ADR related patient's necessary data was obtained and recorded on a pre- designed case record form (CRF).

\section{The data record includes the following}

- General details e.g., name, age, sex, past and present history, general and systemic examination, laboratory investigation, diagnosis and treatment. An adverse drug reaction is documented in details in a separate form which is actually a slight modification of the form prescribed by Central Drug Standard Control Organization (CDSCO) and Pharmacovigilance Programme of India (PVPI) for this purpose.

- This form contains the details of general patient characteristics, adverse drug event, suspected medication, treatment of ADR and its outcome.

\section{A causality analysis of all the observed ADRs}

It is undertaken as per the WHO-UMC and Naranjo probability score, Hartwig and seigel for severity assessment scales, Schumock and thornton for Preventability assessment scales The data collected in the manner described above will be analyse under various heads to ascertain the characteristics of the ADR.

- Important heads of analysis are listed below

- Patient population

- Incidence of ADRs

- Age and gender of patients

- Suspected drugs

- Route of administration of suspected drugs

- Duration of ADRs

- Response to de-challenge/re-challenge 
- Extent of poly-pharmacy in suspected ADRs

- Causality assessment of ADRs WHO-UMC

- Seriousness of ADRs

- Preventability of ADRs

- Severity of ADRs.

\section{RESULTS}

For the study purposes the patient's data were divided into two groups,

- Group A: patients that were admitted for other ailments (other than an ADR) but developed the ADRs during hospitalisation and

- Group B: those patients that were admitted primarily due to the ADRs that developed outside the hospital.

\section{Patient population}

Total numbers of 1536 patient's data were screened. 1464 patient's data had no ADR. Out of the remaining data, 56 developed the ADRs during hospitalisation (group A) and 16 patients were admitted primarily for the treatment of ADRs that developed outside the hospital (group B).Total of 72 patient had the ADRs in the Psychiatry units in the study period of 4 years.

\section{Incidence of ADRs}

- Incidence of the ADRs in our study was $4.68 \%(\mathrm{n}=$ 1536). We found that 56 patients $(3.64 \% \mathrm{n}=1536)$ developed the ADRs during hospitalisation (group A) while in 16 patients $(1.04 \% \mathrm{n}=1536)$ ADRs themselves were the reason for their hospitalisation (group B)

- Total numbers of 101 ADRs were reported in 72 patients. Out of 101 total ADRs, 76 (75.2\%) were reported in group A and the remaining 25 (24.7\%) were seen in group B.

\section{Age and gender of patients}

Table 1: Gender wise distribution of patient.

\begin{tabular}{|llll|}
\hline Gender & $\begin{array}{l}\text { Patients with } \\
\text { ADR }\end{array}$ & $\begin{array}{l}\text { Patients } \\
\text { without ADR }\end{array}$ & Total \\
\hline Male & $49(68.05)$ & 774 & 823 \\
\hline Female & $23(31.94)$ & 690 & 713 \\
\hline Total & $72(100)$ & 1494 & 1536 \\
\hline
\end{tabular}

- Majority of the patient's data that showed the ADRs were in the age group of 37-54 years $(n=35$, $48.61 \%)$. The mean age of the patients who developed ADR was 39.26 years (Figure 1).

- Out of a total number of 1536 patient's data, 823 patients were male and the remaining 713 were female. The incidence of the ADRs in male patients was $5.95 \%(49 / 823)$ and that was found $3.22 \%$,
(23/713) in case of female patients. The male: female ratio was $2.12 \%$ (Table 1 ).

Out of total 72 patients more ADRs were reported in male patients $(49,68 \%)$ than in female patients $(23,31.9 \%)$ (Figure 2).

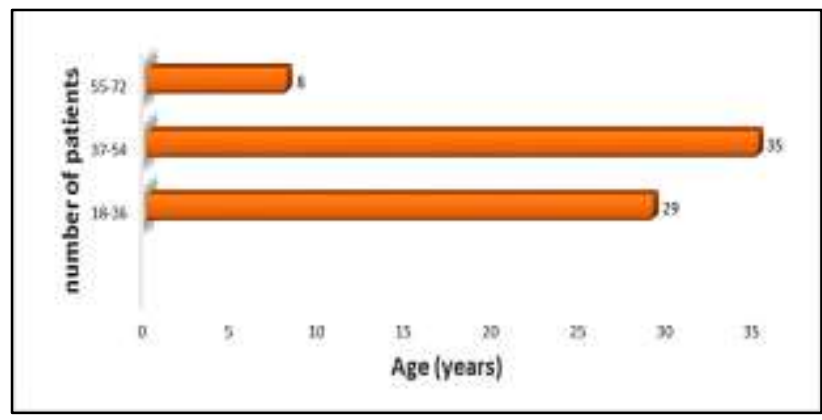

Figure 1: Age wise distribution $(n=72)$.

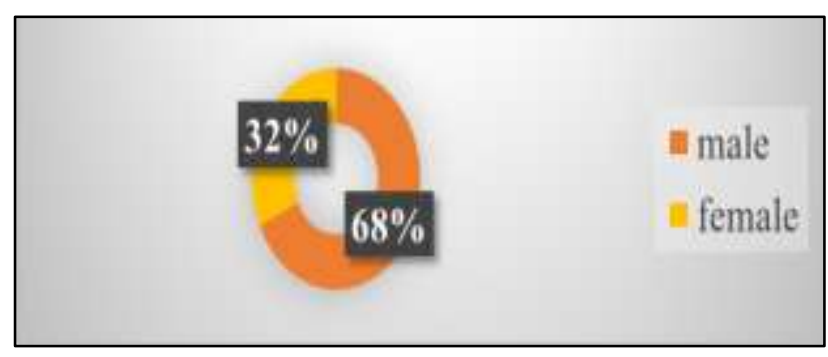

Figure 2: Gender wise distribution of patient $(n=72)$.

\section{Type of ADRs}

Out of total 101 ADRs, were subdivided as type A (Augmented) and type B (Bizarre). Most of the ADRs were of type A which is total 100 (99.01\%). These ADRs were dose related and the pharmacological reactions that usually subside with stoppage of drug/reduction in dose. A total of $1(0.99 \%)$ ADRs were of type B that were not dose related, immunologically mediated reactions, usually occurring in few susceptible patients. Type A and B ADRs were seen significantly more in group A and B respectively Table 2 .

Table 2: Type of ADRs $(\mathbf{n}=101)$.

\begin{tabular}{|llll|}
\hline Type of ADRs & \multicolumn{3}{l|}{ Number of ADRs (\%) } \\
\hline & Group A & Group B & Total \\
\hline Type A & $76(100)$ & $24(96)$ & $100(99.01)$ \\
\hline Type B & 00 & $1(4)$ & $1(0.99)$ \\
\hline Total & $\mathbf{7 6 ( 1 0 0 )}$ & $\mathbf{2 5 ( 1 0 0 )}$ & $\mathbf{1 0 1}(\mathbf{1 0 0})$ \\
\hline
\end{tabular}

\section{Onset of ADRs}

A study of association between the time of drug intake and the onset of ADR showed that most of the adverse drug reactions $48(47.52 \%)$ developed within 1 to 6 month of drug intake. Only $6(5.94 \%)$ of the ADRs were 
reported to have developed more than 12 month of drug administration (Figure 3).

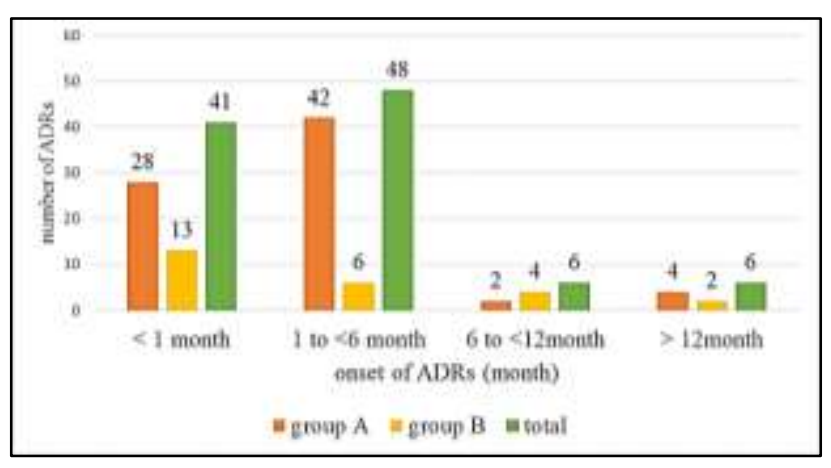

Figure 3: Onset of ADRs $(\mathbf{n}=\mathbf{1 0 1})$.

\section{Onset of treatment}

Out of 101 ADRs, in $47(46.53 \%)$ ADRs treatment was begun immediately, while in $54(53.46 \%)$ ADRs no treatment was given because of mild nature of ADRs. As expected, most of the ADRs in group A were treated immediately (patients already hospitalised) while it took about 1 to 7 days to begin the treatment in patients belonging to group B (patients suffered ADRs outside the hospital) (Table 3).

Table 3: Onset of treatment $(n=101)$.

\begin{tabular}{|llll|}
\hline $\begin{array}{l}\text { Onset of } \\
\text { treatment }\end{array}$ & \multicolumn{3}{c|}{ No of ADRs (\%) } \\
\hline $\begin{array}{l}\text { Immediate } \\
\text { Treatment }\end{array}$ & $34(44.73)$ & $13(52)$ & $47(46.53)$ \\
\hline No treatment & $42(55.26)$ & $12(48)$ & $54(53.46)$ \\
\hline Total & $\mathbf{7 6 ( 1 0 0 )}$ & $\mathbf{2 5 ( 1 0 0 )}$ & $\mathbf{1 0 1 ( 1 0 0 )}$ \\
\hline
\end{tabular}

ADR categorization according to anatomical system ${ }^{3}$

Most common ADR were mainly tremor 14 (13.86\%), salivation11 (10.89\%) followed by muscle rigidity6 $(5.94 \%)$ and slurring of speech $6(5.94 \%)$ (Figure 4$)$ and (Table 4).

Table 4: ADR categorization $(n=101)$.

\begin{tabular}{|ll|}
\hline ADRs & Total \\
\hline Tremor & $14(13.86 \%)$ \\
\hline Salivation & $11(10.89 \%)$ \\
\hline Rigidity & $6(5.94 \%)$ \\
\hline Slurring of speech & $6(5.94 \%)$ \\
\hline Restlessness & $4(3.96 \%)$ \\
\hline Weight gain & $4(3.96 \%)$ \\
\hline Stiffness & $3(2.97 \%)$ \\
\hline Perioral movement & $3(2.97 \%)$ \\
\hline Polyuria & $3(2.97 \%)$ \\
\hline Polydipsia & $3(2.97 \%)$ \\
\hline Muscle dystonia & $3(2.97 \%)$ \\
\hline
\end{tabular}

\begin{tabular}{|ll|}
\hline Blurring of vision & $3(2.97 \%)$ \\
\hline Acute dystonia & $3(2.97 \%)$ \\
\hline Vomiting & $2(1.98 \%)$ \\
\hline Constipation & $2(1.98 \%)$ \\
\hline Akathasia & $2(1.98 \%)$ \\
\hline Dryness of mouth & $2(1.98 \%)$ \\
\hline Itching & $2(1.98 \%)$ \\
\hline Rashes & $2(1.98 \%)$ \\
\hline Protrusion of tongue & $2(1.98 \%)$ \\
\hline Increase talkativeness & $1(0.99 \%)$ \\
\hline Increase breathlessness & $1(0.99 \%)$ \\
\hline Decrease appetite & $1(0.99 \%)$ \\
\hline Decrease sleep & $1(0.99 \%)$ \\
\hline Abdominal pain & $1(0.99 \%)$ \\
\hline Ataxia & $1(0.99 \%)$ \\
\hline Difficulty to close mouth & $1(0.99 \%)$ \\
\hline Elevation of eyebrow & $1(0.99 \%)$ \\
\hline Extra pyramidal symptoms & $1(0.99 \%)$ \\
\hline Fearfulness & $1(0.99 \%)$ \\
\hline Headache & $1(0.99 \%)$ \\
\hline Hyperglycaemia & $1(0.99 \%)$ \\
\hline Irritable mood & $1(0.99 \%)$ \\
\hline Mask like face & $1(0.99 \%)$ \\
\hline Mental confusion & $1(0.99 \%)$ \\
\hline Nausea & $1(0.99 \%)$ \\
\hline Nephrotoxicity & $1(0.99 \%)$ \\
\hline Postural hypertension & $1(0.99 \%)$ \\
\hline Sedation & $1(0.99 \%)$ \\
\hline Tardive dyskinesia & $1(0.99 \%)$ \\
\hline Weakness & $1(0.99 \%)$ \\
\hline & \\
\hline
\end{tabular}

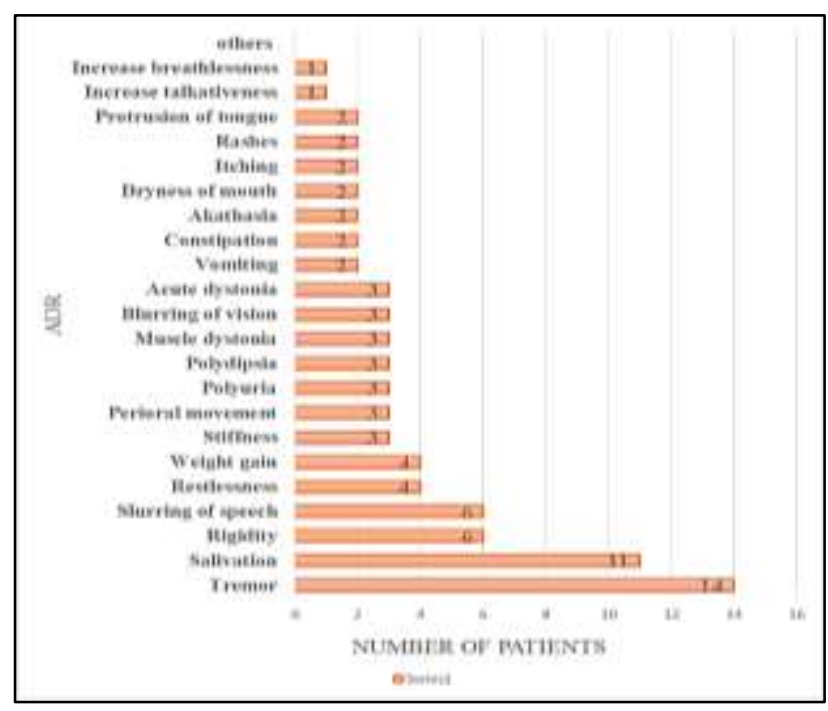

Figure 4: ADRs presentation.

\section{ADRs distribution according to drug class}

In majority of the instances, it was Antipsychotic agents $41(56.94 \%)$ followed by drugs of antidepressant $11(15.27 \%)$ and drugs of mod stabilizer $11(15.27 \%)$ (Table 5). 
Table 5: ADRs distribution according to drug class.

\begin{tabular}{|c|c|c|c|c|}
\hline \multirow{2}{*}{ Groups } & \multirow{2}{*}{ Drug } & \multicolumn{2}{|c|}{ No. of medications } & \multirow{2}{*}{$\begin{array}{l}\text { Total No. of suspected } \\
\text { medications }\end{array}$} \\
\hline & & Group A & Group B & \\
\hline \multirow[t]{8}{*}{ Antipsychotic } & Clozapine & $3(10.71 \%)$ & 0 & $3(7.31 \%)$ \\
\hline & Haloperidol & $10(3.57 \%)$ & $2(15.38 \%)$ & $12(29.26 \%)$ \\
\hline & Olanzapine & $2(7.14 \%)$ & 0 & $2(4.87 \%)$ \\
\hline & Risperidone & $11(39.28 \%)$ & $7(53.84 \%)$ & $18(43.90 \%)$ \\
\hline & Trifluoperazine & $2(7.14 \%)$ & $2(15.38 \%)$ & $4(9.75 \%)$ \\
\hline & Quetiapine & 0 & $1(7.69 \%)$ & $1(2.43 \%)$ \\
\hline & Trifluperidol & 0 & $1(7.69 \%)$ & $1(2.43 \%)$ \\
\hline & Total & $28(100 \%)$ & $13(100 \%)$ & $41(100 \%)$ \\
\hline \multirow[t]{5}{*}{ Antidepressant } & Clomipramine & $1(9.09 \%)$ & 0 & $1(9.09 \%)$ \\
\hline & Fluoxetin & $1(9.09 \%)$ & 0 & $1(9.09 \%)$ \\
\hline & Imipramine & $8(72.72 \%)$ & 0 & $8(72.72 \%)$ \\
\hline & Sertraline & $1(9.09 \%)$ & 0 & $1(9.09 \%)$ \\
\hline & Total & $11(100 \%)$ & $\mathbf{0}$ & $11(100 \%)$ \\
\hline \multirow[t]{5}{*}{ Antiepileptic } & Carbamazepine & $2(25 \%)$ & 0 & $2(25 \%)$ \\
\hline & Divalproex & $1(12.5 \%)$ & 0 & $1(12.5 \%)$ \\
\hline & Lorazepam & $1(12.5 \%)$ & 0 & $1(12.5 \%)$ \\
\hline & Sodium valproate & $4(50 \%)$ & $1(100 \%)$ & $5(50 \%)$ \\
\hline & Total & $8(100 \%)$ & $1(100 \%)$ & $9(100 \%)$ \\
\hline \multirow[t]{2}{*}{ Mood stabilizer } & Lithium & $9(100 \%)$ & $2(100 \%)$ & $11(100 \%)$ \\
\hline & Total & $9(100 \%)$ & $2(100 \%)$ & $11(100 \%)$ \\
\hline
\end{tabular}

It was observed from patient's data that risperidone 19 (46.34\%), haloperidol 13 (31.7\%), lithium 12 (100\%) and Imipramine $8(57.14 \%)$ were most frequently suspected drugs in group A while risperidone 10 (45.45\%), trifluoperazine $4(18.18 \%)$ and quetiapine $4(18.18 \%)$ were the common causes of ADRs requiring hospitalisation in group B (Figure 5).

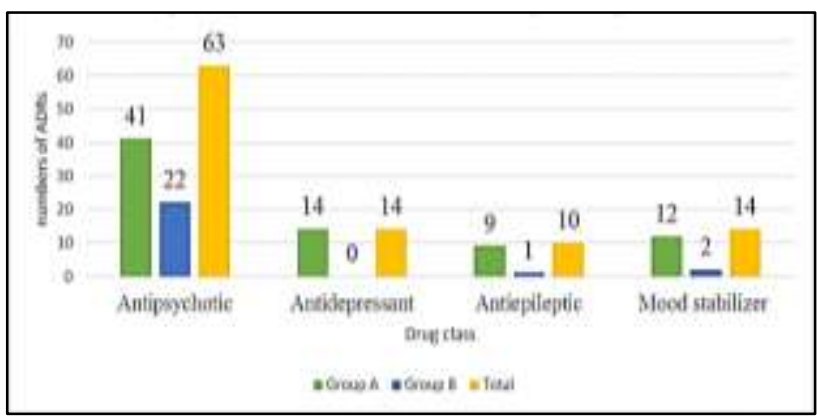

Figure 5: ADRs distribution according to drug class.

\section{ADR categorization according to anatomical system ${ }^{9}$}

Systems affected by the ADRs are shown in (Table 6). A large number of ADRs 70 (69.30\%) belonged to Central and peripheral nervous system and Gastrointestinal system 8 (7.92\%). This was followed by Metabolic and nutritional system and Skin. ADRs pertaining to Endogenous system and respiratory tract were reported rarely (Table 6).

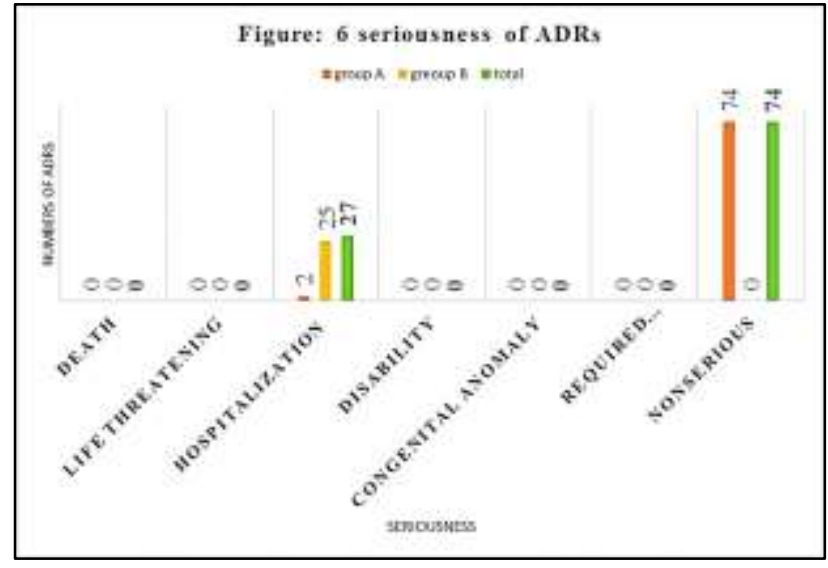

Figure 6: Seriousness of ADRs.

Table 6: ADR categorization according to anatomical system $(\mathbf{n}=101)$.

\begin{tabular}{|lll|l|}
\hline System & $\begin{array}{l}\text { Total ADRs } \\
(\%)\end{array}$ & Symptom & Total \\
\hline $\begin{array}{l}\text { Central } \\
\text { and } \\
\text { peripheral } \\
\text { nervous } \\
\text { system }\end{array}$ & $70(69.3 \%)$ & Tremor & $14(20.2 \%)$ \\
\hline & Salivation & $11(15.9 \%)$ \\
\hline & Rigidity & $6(8.6 \%)$ \\
\hline & $\begin{array}{l}\text { Slurring of } \\
\text { speech }\end{array}$ & $6(8.6 \%)$ \\
\hline & Restlessness & $4(5.7 \%)$ \\
\hline
\end{tabular}




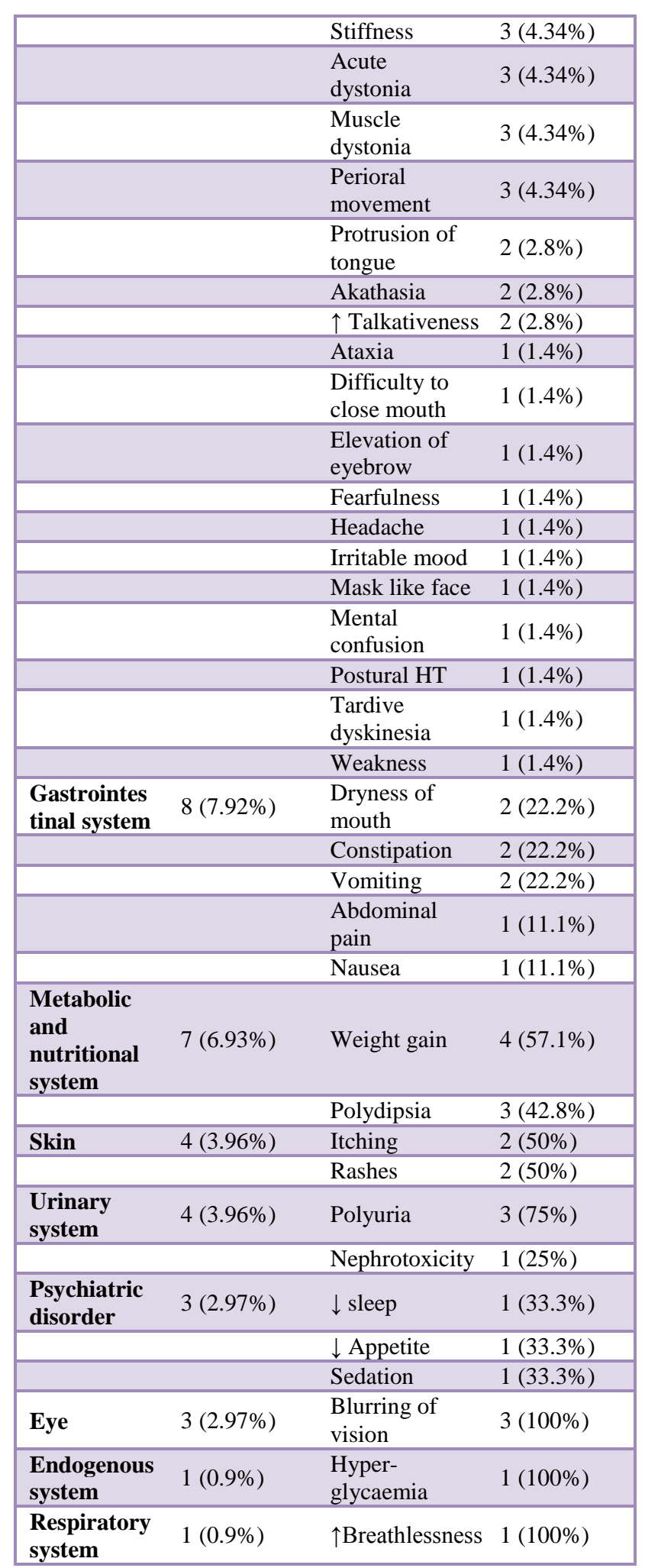

\section{Further analysis of the reported ADRs is given below}

The Central and peripheral system ADRs were mainly, Tremor (14), Salivation (11), Rigidity (6), Slurring of speech (6), Restlessness (4), Stiffness (3) and Acute dystonia (3).

\section{Clinical diagnosis}

Schizophrenia $25(34.72 \%)$ was the most commonest clinical diagnosis followed by Bipolar mood disorder 24 $(33.33 \%)$ and Major depressive disorder $12(16.66 \%)$ (Table 7).

Table: 7 Clinical diagnoses.

\begin{tabular}{|ll|}
\hline Disorder & n (\%) \\
\hline Schizophrenia & $25(34.72 \%)$ \\
\hline Bipolar mood disorder & $24(33.33 \%)$ \\
\hline Major depressive disorder & $12(16.66 \%)$ \\
\hline Psychosis & $6(8.33 \%)$ \\
\hline Mania & $2(2.63 \%)$ \\
\hline Mental illness & $1(1.38 \%)$ \\
\hline Dysthymia & $1(1.38 \%)$ \\
\hline Pervasive development disorder & $1(1.38 \%)$ \\
\hline Total & $\mathbf{7 2 ( 1 0 0 \% )}$ \\
\hline
\end{tabular}

\section{Route of administration of drugs}

Suspected medication was usually administered by oral $99(98.01 \%)$ or intravenous route $1(0.99 \%)$ or intramuscular route $1(0.99 \%)$.

\section{Outcome of ADRs}

Table 8: Outcome of ADRs.

\begin{tabular}{|llll|}
\hline \multirow{2}{*}{ Outcome } & \multicolumn{3}{c|}{ No. of ADRs (\%) } \\
& Group A & Group B & Total \\
\hline Recovered & $18(23.68 \%)$ & $10(40 \%)$ & $28(27.72 \%)$ \\
\hline Recovering & $33(43.42 \%)$ & $12(48 \%)$ & $45(44.55 \%)$ \\
\hline Continuing & $25(32.89 \%)$ & $3(12 \%)$ & $28(28.72 \%)$ \\
\hline Fatal & 0 & 0 & 0 \\
\hline Total & $\mathbf{7 6 ( 1 0 0 \% )}$ & $\mathbf{2 5 ( 1 0 0 \% )}$ & $\mathbf{1 0 1}(\mathbf{1 0 0 \% )}$ \\
\hline
\end{tabular}

Table 8 shown in group A 18 (23.68\%) of ADRs were in recovered category, $33(43.42 \%)$ of ADR were in recovering category and $25(32.89 \%)$ of ADR were in continuing category. while in group B $10(40 \%)$ of ADRs were in recovered phase, $12(48 \%)$ of ADR were in recovering phase and $3(12 \%)$ of ADR in continuing phase. Considering total ADRs, out of total 101 ADRs 45 (44.55\%) ADRs were recovering which were maximum in number (Table 8 ).

\section{Seriousness of the ADRs}

Adverse drug reactions were categorized as serious or non-serious based on WHO classification. From patient's data, out of 101 reports, 27 (26.73\%) ADRs were considered to be serious and 74 (73.26\%) ADRs to be non-serious. We further divided the serious and nonserious ADRs in group $\mathrm{A}$ and $\mathrm{B}$. We found that in observed 74 non-serious ADRs 74 belonged to group A and 0 in group $B$. In the same manner, 25 serious ADRs were seen in group B and 2 serious ADRs in group A 
(Figure 6). However, we did not encounter any serious ADRs such as death, disability and congenital anomaly in any of the groups. In conclusion, most of the ADRs in group A were non-serious and all those in B were of serious nature.

\section{Causality assessment of ADRs}

The causality assessment of the ADRs was carried out from patient's data using both the WHO-UMC criteria (Figure 7) and Naranjo's scale (Figure 8). ${ }^{10,11}$

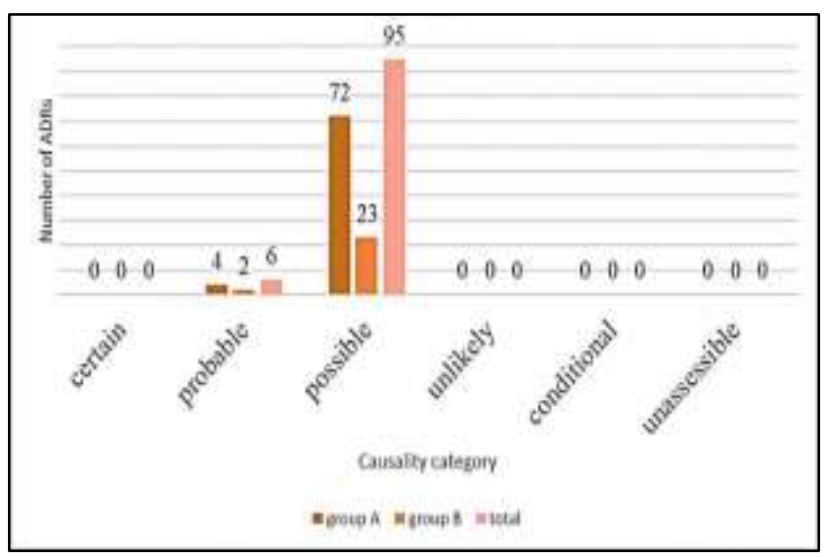

Figure 7: Causality assessment of ADRs (WHO-UMC criteria).

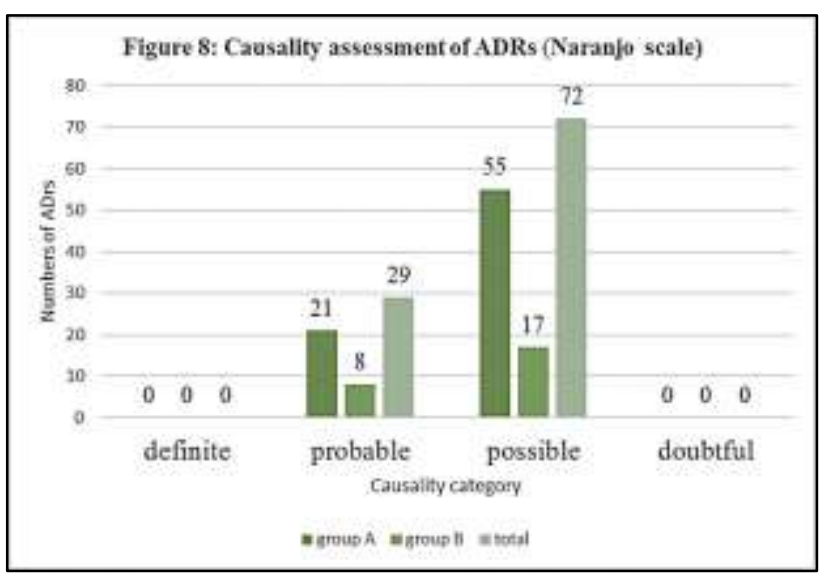

Figure 8: Causality assessment of ADRs (Naranjo scale).

- WHO-UMC scale - a causality assessment carried out from patient's data as per WHO-UMC criteria revealed that the majority of the cases in group A 72 $(94.73 \%)$ and B $23(92 \%)$ were possible. 4 (5.26\%) cases belonged to 'probable' category in group A and such cases were $2(8 \%)$ in group B.

- Naranjo scale - as observed in WHO-UMC criteria, in Naranjo scale also most of the causality assessments were either probable or possible in group A and in group B. $21(27.63 \%)$ cases belonged to 'probable' category in group A and such cases were 8 $(32 \%)$ in group B. Similarly, in the 'possible' category $55(72.36 \%)$ cases were there in group A and only 17 (68\%) cases in group B.

A closer scrutiny of results underlined the fact that even in the individual categories of 'probable' and 'possible', the results were slightly more varied amongst group A than group B. Thus, total $6(5.94 \%)$ cases were probable and $95(94.05 \%)$ cases were possible in WHO-UMC criteria and these were total $29(28.71 \%)$ cases were probable and $72(71.28 \%)$ cases were possible in Naranjo scale respectively.

\section{Severity of $A D R s^{12}$}

From patient's data, analysis of the severity of ADRs was done according to Hartwig seigle's scale. It is evident that majority of ADRs 74 (73.26\%) was mild in severity (Figure 9).

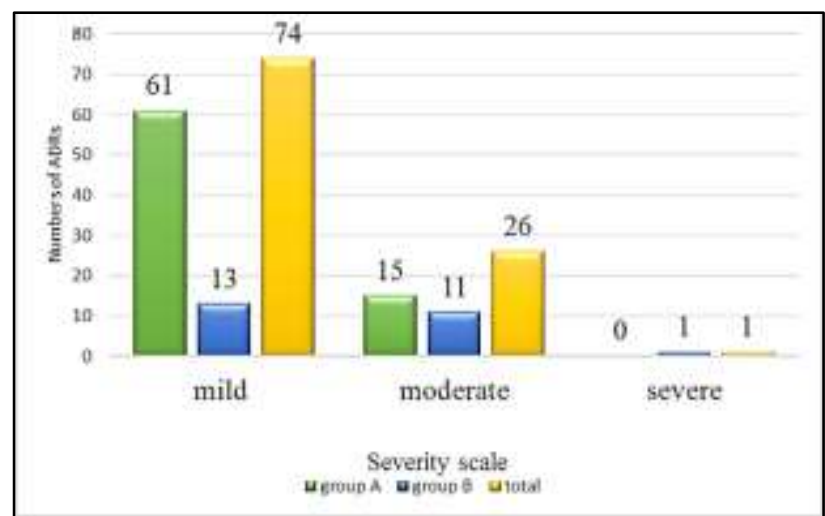

Figure 9: severity scale (Modified Hartwig and Siegel).

A total number of 26 (25.74\%) ADRs were moderate in severity. A total number of $1(0.99 \%)$ ADR were severe in nature. Out of 74 mild ADRs, we observed 61 (80.26\%) ADRs in group A and 13 (52\%) ADRs in group B while out of 26 moderate ADRs, majority of them 15 $(19.73 \%)$ were exhibited in group A and $11(44 \%)$ in group B.

\section{Preventability scale s $^{13}$}

Out of the total of $10(9.90 \%)$ preventable ADRs, majority $8(10.52 \%)$ belonged to group A and only a small number $2(8 \%)$ to group B. Total $91(90.09 \%)$ ADRs were not preventable and from them $68(89.47 \%)$ belonged to group A and 23 (92\%) belonged to group B. Out of a total number of 25 ADRs that causes the hospital admission in patients of group B, 23 (92\%) were not preventable.

\section{DISCUSSION}

A total of 1536 patient's data were screened during the study period. Out of this, 72 patients were found to have the ADRs and therefore the incidence was $4.68 \%$. A total number of 101 ADRs were reported in 72 patients. This 
was made up of $56(3.64 \%)$ patients that developed 76 ADRs during hospitalisation (group A) and 16 (1.04\%) of those patients that developed 25 ADRs were admitted primarily for the treatment (group B). However, if total population of the patient's data studied (1536) is taken into account for the distribution of 101 ADRs then the incidence comes to be around $0.04 \mathrm{ADR} /$ patient. Lucca JM et al. Study shows average no. of ADR per patients is $1.6 .^{14}$

We have detected the incidence of ADRs to be $4.68 \%$ of the patient's data. This is less than what has been observed in Kuruvilla A et al and Lucca JM et al. ${ }^{7,14}$ studies and the incidence recorded is $32.6 \%$ and $38.38 \%$ respectively. Most of these studies had taken into account either the total hospital admissions or all the patients admitted to particular specialities (for example, Medicine, TB and Chest etc.). However, it is possible that patients receiving certain special groups of drugs, e.g., anticancer and anti-tubercular medications were also included in these studies. These drugs are likely to produce a greater number of adverse drug reactions and therefore a higher incidence is likely to be recorded.

Patient's data that majority $48.61 \%$ of our patients belonged to the age group of 37-54 years. The mean age of the patients who developed ADR was 39.26 years in our study. Kuruvilla A et al study reported that majority $61.4 \%$ of patients belonged to the age group of 20-39 years. Shah LP et al. ${ }^{7,15}$ Study reported that mean age of the patients who developed ADR was 34.8 years. Lucca JM et al study shows that mean age of the patients who developed ADR was 34.5 years Rothschild JM et al. ${ }^{14,17}$ study shows that mean age of the patients was 43.4 years. Our study has provided a further support to this observation.

We have observed from patient's the data that out of the total patient population about $31.94 \%$ females and $68.05 \%$ of males were affected by the ADRs. Thus, we have observed that higher number of incidence of ADRs in males in this study. This result supported by Kurmi P et al study which also shows that higher incidence of ADRs has been reported for males $54.87 \%$ and $45.12 \% \%$ in females. ${ }^{16}$ From patient's data, we observed that in our study majority of patient had onset of ADRs within 1- 6 month which is $48(47.52 \%)$ and this data is not comparable to Kuruvilla A et al study, $65 \%$ patient had onset of ADRs after 1 week and $35 \%$ patient had onset of ADRs within week (2-5 days). ${ }^{7}$ It is possible that hospitalised patients are usually admitted for acute conditions and in these patients any new symptoms or laboratory abnormalities are quickly observed, documented and treated. On the other hand, patients developing the ADRs outside the hospital are usually on chronic medication and hence they either developed the ADRs after a substantial lag period or they report them quite late.
From patient's data, the present study has shown that most common reported ADR were mainly tremor 14 $(13.86 \%)$, salivation $11(10.89 \%)$ followed by muscle rigidity $6(5.94 \%)$, slurring of speech $6(5.94 \%)$ and Weight gain $4(3.96 \%)$. A number of authors have reported nearly the same observations in Kuruvilla A et al and Kurmi $\mathrm{P}$ et al study. ${ }^{7,16}$ Luppa CA et al study has shown that most common reported ADR are Acute dystonia, Akathasia, Pseudo parkinsonism. ${ }^{8}$ Shah LP et al study shows that most common ADR are Drowsiness, Constipation, Dryness of mouth and Giddiness. ${ }^{15}$ Lucca JM et al study shows Weight gain as most common ADR. ${ }^{14}$

Patent's data has shown that most commonly reported ADRs occurred at Central and peripheral nervous system $(68.3 \%)$ followed by gastrointestinal tract $(8.91 \%)$, Metabolic and nutritional system (6.93\%) and Skin $(3.96 \%)$ in that order. A number of authors have reported the same observations in Lucca JM et al and Rothschild JM et al study. ${ }^{14,17}$

We have further observed from patient's data that Antipsychotic agents $41(56.94 \%)$ followed by drugs of antidepressant $11(15.27 \%)$ and drugs of mod stabilizer $11(15.27 \%)$ are a frequent cause of adverse drug reactions. Most of the other studies like Luppa CA et al Kuruvilla A et al and Rothschild $\mathrm{J} \mathrm{m}$ el al have reported Antipsychotic is most common drug class for ADRs. ${ }^{7,8,18}$

From patient's data, our study was observed that risperidone 19 (46.34\%), haloperidol $13(31.7 \%)$, lithium $12(100 \%)$ and imipramine $8(57.14 \%)$ were most frequently suspected drugs in group A while risperidone $10(45.45 \%)$, trifluoperazine $4(18.18 \%)$ and quetiapine 4 (18.18\%) were the common causes of ADRs requiring hospitalisation in group B.

In Our study, Schizophrenia 25(34.72\%) was the most common clinical diagnosis followed by bipolar mood disorder $24(33.33 \%)$ and Major depressive disorder 12 $(16.66 \%)$. diagnosis followed by Bipolar mood disorder and Major depressive disorder.

We have observed that in WHO-UMC criteria majority of the ADRs in group A and group B were 'possible'. However, we have further seen that in Naranjo scale in both the groups, 'possible' were maximum and Naranjo scale.

Our findings are not in agreement with these authors when we compare a total of 'probable' and 'possible' categories. We have, however, experienced that the WHO-UMC method is simple and less time consuming.

On the other hand, the Naranjo scale covers many more aspects of ADR profile but it is subjective. (Alternate causes, placebo effects, past history, blood concentration of drug etc.). 
We have carried out the Preventability assessment of the ADRs on the basis popular methods used for this purpose, namely Schumock and Thornton scale. In our study most of the ADRs are not preventable and this is in accordance with Rothschild JM et al. ${ }^{17}$

We have seen from patient's data that majority of the ADRs $(73.26 \%)$ observed by us were mild in nature in severity scale. Lucca CA et al, which is not as supportive to study reported that $86 \%$ of the ADRs in their study were made up of 'moderate' and $12.5 \%$ of ADRs in 'severe' categories in Modified Hartwig and Siegel. ${ }^{18}$

- In our present study, incidence of ADR was $4.68 \%$ (n $=72$, total no $=1536$ )

- Among total no of 101 ADRs reported, 56 (3.64\%) patients developed ADRs in group A while 16 (1.04\%) patients from group B

- Majority of the patient' data that showed the ADRs were in the age group of $37-54$ years $(48.61 \%)$. The mean age of the patients who developed ADR was 39.26 years.

- Out of a total number of 1536 patient's data, 823 patients were male and the remaining 713 were female. The incidence of the ADRs in male patients was $5.95 \%(49 / 823)$ and that was found $3.22 \%$, $(23 / 713)$ in case of female patients. The male: female ratio was $2.12 \%$.

- Most of the adverse drug reactions 48 (47.52\%) developed within 1 to 6 month of drug intake. only 6 (5.94\%) ADRs were developed after 12 month of drug administration.

- Out of 101 reports, $27(26.73 \%)$ ADRs were considered to be serious and 74 (73.26\%) ADRs to be non-serious.

- Out of 101 ADRs, in $47(46.53 \%)$ ADRs treatment was begun immediately, while in 54 (53.46\%) ADRs no treatment was given because of mild nature of ADRs.

- Most common ADR were mainly tremor 14 (13.86\%), salivation $11(10.89 \%)$ followed by muscle rigidity $6(5.94 \%)$ and slurring of speech $6(5.94 \%)$ Suspected medication was usually Administered by oral $99(98.01 \%)$ or intravenous route $1(0.99 \%)$ or intramuscular route $1(0.99 \%)$.

- Considering total ADRs, out of total 101 ADRs 45 (44.55\%) ADRs were recovering which were maximum in number. In group A $18(23.68 \%)$ of ADRs were in recovered category, $33(43.42 \%)$ of ADR were in recovering category and 25 (32.89\%) of ADR were in continuing category. while in group B $10(40 \%)$ of ADRs were in recovered phase, 12 $(48 \%)$ of ADR were in recovering phase and $3(12 \%)$ of ADR in continuing phase.

- As per causality assessment by WHO-UMC and Naranjo criteria. 95 (94.05\%) cases were 'possible' in WHO-UMC criteria and $7271.28 \%$ ) cases were 'possible' in Naranjo scale respectively.
- As per Schumock and Thornton preventability assessment, about 91 (90.09\%) of total ADRs were in the not-preventable category.

- As per Hartwig and seigle's severity assessment, Majority of ADRs 74 (73.26\%) was mild in severity.

- A large number of ADRs $69(68.31 \%)$ belonged to central and peripheral nervous system and gastrointestinal system $8(8.91 \%)$. This was followed by metabolic and nutritional system and Skin. ADRs pertaining to endogenous system and respiratory tract were reported rarely.

- In majority of the instances, it was Antipsychotic agents $41(56.94 \%)$ followed by Antidepressants $11(15.27 \%)$ and mood stabilizers $11(15.27 \%)$. It was observed that risperidone $19(46.34 \%)$, Haloperidol $13(31.7 \%)$, lithium $12(100 \%)$ and Imipramine 8 $(57.14 \%)$ were most frequently suspected drugs in group A while risperidone 10 (45.45\%), trifluoperazine 4 (18.18\%) and quetiapine 4 (18.18\%) were the common causes of ADRs requiring hospitalisation in group B.

- Schizophrenia $25(34.72 \%)$ was the most common clinical diagnosis followed by bipolar mood disorder $24(33.33 \%)$ and major depressive disorder 12 $(16.66 \%)$

Inter-current illness, longer hospital stay and poly pharmacy will play a major role in occurrence of multiple adverse drug reactions. Management of such ADRs through therapeutic interventions would have resulted in better patient outcome. Developing an on-going adverse drug reaction reporting system with continuous motivation and creating awareness among the healthcare professionals for reporting suspecting adverse drug reactions will help to continue reporting and improving the patient's safety.

\section{ACKNOWLEDGEMENTS}

Authors would like to acknowledging Institutional Ethics Committee for approval and Head of Department and Faculties of Department of Psychiatry and pharmacology, MPSMC, Jamnagar for providing support and facilities.

Funding: No funding sources Conflict of interest: None declared

Ethical approval: The study was approved by the Institutional Ethics Committee

\section{REFERENCES}

1. Tripathi KD, Essentials of Medical Pharmacology. $7^{\text {th }}$ ed. Jaypee Brothers medical publishers, New Delhi, India; 2009:82-92.

2. Vora MB, Trivedi HR, Shah BK, Tripathi CB. Adverse drug reactions in inpatients of internal medicine wards at a tertiary care hospital: a prospective cohort study. Journal of pharmacology and pharmacotherapeutics. 2011;2(1):21-5. 
3. Pimpakhute SA, Jaiswal KM, Sontakke SD, Bajait CS, Gaikwad A. Evaluation of awareness about pharmacovigilance and adverse drug reaction monitoring in resident doctors of a tertiary care teaching hospital. Indian J Med Sci. 2012;66(34):5561.

4. Cruz SD, Sachdev A, Tiwari P. Adverse drug reactions and their risk factors among Indian ambulatory elderly patients. Indian J Med Res. 2012;136:404-10.

5. Pimpalkhute SA, Jaiswal KM, Sontakke SD, Bajait CS, Gaikwad A. Evaluation of awareness about pharmacovigilance and adverse drug reaction monitoring in resident doctors of a tertiary care teaching hospital. Indian Juornal of Medical Science. 2012;66(3):55-61.

6. Prajapati HK, Joshi ND, Trivedi HR, Parmar MC, Jadav SP, Parmar DM, et al. Adverse drug reaction monitoring in psychiatric outpatient department of a tertiary care hospital. National Journal of Integrated Research in Medicine. 2013;4(2):102-6.

7. Kuruvilla A, Kuruvilla K. Incidence of severe reaction to commonly prescribed psychopharmacological agents during early phase of therapy. Indian J PsychiaL. 1995;37(3):113-8.

8. Iuppa AC, Nelson LA, Elliott E, Sommi RW. Adverse drug reactions: a retrospective review of hospitalized patients at a state psychiatric hospital. Hosp Pharm. 2013;48(11):931-5.

9. Hartwing S, Seigel J. Preventability and severity assessment in reporting adverse drug reactions. Am J Hosp Pharm. 1992;49:2229-32.
10. The use of the WHO-UMC system for standardized case causality assessment, 2012. Available at http://www.who umc.org/graphics/4409.pdf.

11. Naranjo CA, Busto U, Sellers EM, Sandor P, Ruiz I, Roberts EA, et al. A method for estimating the probability of adverse drug reactions. Clin Pharmacol Ther. 1981;30(2):239-45.

12. Hartwing S, Seigel J. Preventability and severity assessment in reporting adverse drug reactions. Am J Hosp Pharm. 1992;49:2229-32.

13. Schumock GT, Thornton JP. Focusing on the preventability of adverse drug reactions. Hosp Pharm. 1992;27:538.

14. Lucca JM, Madhan R, Parthasarathi G, Ram D. Identification and management of adverse effects of antipsychotics in a tertiary care teaching hospital. Journal of Research in Pharmacy Practice. 2014;3(2):247-54.

15. Shah LP, Ayyar KP, Agrawal BR, Pradha PV. Drug surveillance programme in psychiatry adverse drug reaction. Indian J Psychiaty. 1983;25(3):229-34.

16. Kurmi P, Paul PK, Dutta SK, Das S, To Study the Pattern of Adverse Drug Reaction of Antipsychotic Drugs in a Tertiary Care Hospital of Assam, International Journal of PharmTech Research. 2015,8;1:101-5.

17. Rothschild JM, Mann K, Keohane CA, Williams DH, Foskett C, Rosen SL, et al. Medication safety in a psychiatric hospital. General Hospital Psychiatry. 2007;29:156-62.

18. Thomas M, Boggs AA, Paula BD, Siddiqi S. Adverse drug reactions in hospitalized psychiatric patients. The Annals of Pharmacotherapy. 2010;44:819-25.

Cite this article as: Hotha PP, Jadav SP, Trivedi HR. Adverse drug reactions: a retrospective review of hospitalized psychiatric patients at tertiary care hospital. Int J Basic Clin Pharmacol 2016;5:2051-60. 